\title{
John Bennett Fenn: A Curious Road to the Prize
}

\author{
Michael A. Grayson
}

American Society for Mass Spectrometry, 3433 Bluff View Drive, Saint Charles, MO 63303-6608, USA

\begin{abstract}
John Bennett Fenn shared the 2002 Nobel Prize in Chemistry for his development of electrospray ionization (ESI). There are several excellent, in-depth biographical reviews of Fenn's scientific career Fenn (Angew. Chem., Int. Ed. 42, 3871-3894, 2003) and Fenn (Annu. Rev. Phys. Chem. 47, $1-41,1996)$. The focus of this report is to trace the random walk nature of Fenn's career path and to highlight those critical events along that path that led him to the important work for which he was recognized, the development of ESI as a means of ionizing large molecules and interfacing the liquid chromatograph to the mass spectrometer. In addition, this report should hopefully convey something of the curious, generous, kind, and outgoing nature of the man.
\end{abstract}

Key words: History, Nobel Prize, Electrospray, LC-MS

\section{An Inauspicious Beginning}

$\mathrm{J}^{\mathrm{s}}$ ohn Bennett Fenn was born on June 15, 1917 to middle class parents in New York City. Growing up across the Hudson River in Hackensack, New Jersey, there was little in his upbringing to suggest that he would become a Nobel Laureate 85 years later. Perhaps the most important characteristic of those early years was the strong emphasis that his parents placed on education. Both his mother and father were college graduates; she from Columbia University with a degree in Home Economics and Nutrition and he from Rutgers University with a degree in Electrical Engineering. Consequently, it was a given that John was expected to excel in his school work and go on to college.

Perhaps another characteristic impressed on young John came from his father, whose non-linear career path would be a model for him. Herbert Bennett Fenn left Rutgers for a position with the Presbyterian Mission Board to teach at the Sheldon Jackson Mission School in Sitka, Alaska [1]. Subsequently he was employed at the Metacloth Company in Lodi, New Jersey; draftsman for the Fokker Aircraft Company in Teeterboro, New Jersey, [2]; and finally as a teacher in the Industrial Arts Department of the Foundation School and Academy at Berea College and Allied Schools in Berea, Kentucky. Only this latter

Correspondence to: Michael A.Grayson; e-mail: mikeagrayson@gmail.com position was actually related to his formal education in electrical engineering.

Fenn's first 'exposure' to chemistry was not the most pleasant. The Metacloth Company, where his father was superintendent, treated cotton duck cloth with a cupric ammonium solution, thus providing a measure of waterproofing and insect repellent property for tents and other outdoor equipment for use in the tropics. Invited to visit the plant one day, the young Fenn decided to look into one of the treatment vats and found the smell, akin to smelling salts, to be overpowering and unpleasant [1]. Other youthful experiences, which seemed to mitigate against a science career are related in his 1996 reminiscence "Research in Retrospect: Some Biograffiti of a Journeyman Chemist" [2]. For his tenth Christmas he received a Chemcraft chemistry set that did little to "promote much of a reaction on my part because none of the experiments seemed very interesting." Furthermore, his ninth grade algebra teacher returned his first semester exam with the emphatic declaration "Don't ever try to be a scientist or engineer!" This certainly didn't seem to bode well for the future recipient of a Nobel Prize in chemistry.

With the Depression, the loss of a job, and the family savings disappearing in home foreclosure, the Fenn family sought opportunity in Berea, Kentucky, where as noted above, John's father joined the faculty of Berea College in 1928. Started in 1854, Berea was devoted to provide educational opportunities for people of color and the disadvantaged of Appalachia. Forced to shut down during 
the Civil War, it reopened in 1866 with its student body of 187 divided almost equally between black and white students. The school began granting bachelor degrees in 1873 , but it could not legally accept black students for matriculation until 1950 when the Day Law was amended to permit integration above the high school level.

Fenn enrolled in Berea High School in the early 1930s after the move with his family from New Jersey. At the time, it was a wide ranging educational institution, accepting students of all ages from junior high through college. It was comprised of four schools; a foundation junior high school that went through the ninth grade; a 2-year normal school for teacher training; a senior high comprising tenth, eleventh, and twelfth grades known as the Academy, and then a 4-year college. Tuition was free, but students were expected to work at various jobs in the school and on campus. Many of Fenn's classmates were older; people who, because of some hardship or another, had had to interrupt their education. But Berea accepted them if they showed the will to continue their education and they participated in the work study program.

Fenn continued his education at Berea College after completing high school. The experience certainly helped form Fenn's attitude towards hard work, acceptance of others, and maintaining a broad, open mind. And despite earlier indications that science was not his cup of tea, he found a teacher at Berea College who changed that attitude. His freshman chemistry teacher, Julian Capp, was an inspirational teacher and also good friends with Fenn's parents. Fenn recalls Capp fondly [2]:

"He was a great raconteur (as well as a great trencherman), who could recite Milton and Shakespeare. He had a rare sense of humor and an amazing storehouse of knowledge of all kinds, from natural history to soapmaking. Any doubts I might have had were swept away in his freshman chemistry course. He was a magnificent teacher, who made his subject live, in part because he had worked in industry and could relate the classroom to the real world of both commerce and everyday life much more convincingly than did any textbook. I really looked forward to going to class, a sentiment that is rare among today's first-year chemistry students."

It would appear that Capp served as a life model for Fenn, as he was recognized for those same characteristics later in his life [3]. Graduating a year ahead of his class by taking summer courses at the University of Iowa one year, and Purdue University the second year, he was just turning 20 when he received his baccalaureate degree. However, in addition to that mark of a formal education, Berea left him with a disposition that could only be characterized as Southern Gentleman. Whatever was left of his Yankee roots, they were long gone by 1937.

But neither would help him get a job since prospects were still poor due to the Depression. Consequently, he decided to continue his studies in chemistry. He was accepted at both
Northwestern University and Yale University and was prepared to go to the school that had offered him the more lucrative assistantship, Northwestern. However, on the advice of a friend, and the offer of a free ride to Yale, he ended up in New Haven in the fall of 1937. The graduate program in chemistry at the time was very much cut and dried compared with today's regimen. It consisted of a 3year program with a specific set of course work and research; the proportions leaning mostly toward research at the end of the three years. A winnowing process took place after the first year in which the faculty selected who among the class would continue for the remaining 2 years. Those left out were awarded Masters degrees and sent on their way.

Fenn was assigned to work for Gosta "Gus" Akerlof unceremoniously by Professor Herbert Harned, the senior member of the physical chemists then at Yale. Although Fenn was interested in physical chemistry, his graduate research under Akerlof was less than stimulating. He describes the boring research in detail [2].

"In essence what I had to do was measure the potential difference between electrodes of silver-silver chloride and platinum-hydrogen in solutions of $\mathrm{HCl}$ with molalities from 0.01 to 10.0 in solvents comprising methanol in water at intervals of $10 \%$ from 0 to 90 , at temperatures from 0 to $50{ }^{\circ} \mathrm{C}$. I think the total number of emf measurements was around 3000, taking into account that each measurement was made in triplicate, i.e. for each of three separate cells containing the same solution. My routine for most of 2 years was to prepare six cells, two sets of three, each set with the same solution, and let them equilibrate over night with hydrogen bubbling over the platinum electrodes. If the emfs in each set of three cells agreed within some forgotten number of tenths of millivolts, then I would haul 50 pounds or so of ice from the basement to my thermostated bath to bring the temperature down to near $0{ }^{\circ} \mathrm{C}$. The rest of the day would be spent recording emf values for all six cells at every $10^{\circ}$ as the thermostat was heated to 40 or $50^{\circ} \mathrm{C}$, depending on the vapor pressure of the cell solution. All the results were fitted by least squares to a quadratic curve for the dependence of emf on concentration. The least-square calculations were all carried out by a hand-cranked Monroe Calculator, except when I was lucky enough to grab the one electrically driven machine in the calculating room."

While becoming a good friend with Akerlof under his tutelage, the less than stimulating research project left Fenn with little interest in pursuing a position in academia. Certainly, Fenn's graduate experience at Yale held little promise that he would become a Nobel Prize recipient; on research that he would do at Yale a half-century later! Graduating in 1940 with a wife of 1 year, he looked to 
industry with the hope of finding a more stimulating start for his professional career. A position in the research department of the Phosphate Division of Monsanto Chemical Company in Anniston, Alabama seemed to fit the bill and Fenn was soon immersed in solving a series of specific problems associated with the Phosphate Division's major products; phosphate salts, and chlorinated biphenyls, otherwise known as Aroclors.

\section{Towards Nobel Prize Winning Research}

\section{A Serendipitous Meeting}

Despite enjoying a more stimulating work environment than he had at Yale, Fenn soon became disenchanted with the way Monsanto was running the Division and decided to move on in 1943. However, not before a singularly important event in his non-linear path to Stockholm occurred. He met another Monsanto organic chemist with a Ph.D. from Princeton, James W. Mullen II, working with a group to determine a means for the recovery of fatty acids from tall oil, an abundant by-product of pine tree pulp. Mullen had visions that he shared with Fenn of some day starting his own research company. Thinking that Mullen's musings were nothing more than a pipe dream, on departing Monsanto, Fenn went to work for Sharples Chemicals in Wyandotte, Michigan; once again in their research department. At the same time, Mullen left for a brief sojourn in Richmond, Virginia before taking a position at Bell Labs back in New Jersey.

Upon arriving at Sharples, Fenn was immediately pressed into service to help operate a pilot plant for the production of tertiary dodecyl mercaptan, a synthetic substitute for lauryl mercaptan as a "modifier" for the polymerization of butadiene in the manufacture of synthetic rubber. The natural source for lauryl mercaptan was coconut oil, but with World War II raging in the Pacific, the synthetic rubber program was denied this essential compound. As with so many other war related projects during this era, people worked long hours to get the job done as rapidly as possible. Unfortunately, the pilot plant was expected to produce more than it was designed for, and along with frequent breakdowns, caused extra work for all.

After playing his part in getting a new and proper production plant for tertiary dodecyl mercaptan in operation, Fenn was assigned to a job that involved frequent trips to Sharples' patent attorney in Philadelphia. Thus, it was a short train ride to Richmond, Virginia when Jim Mullen II invited Fenn to consider joining his new company, Experiment Incorporated. It turned out that Mullen was having an actual pipe dream when he described his ambitions to Fenn in Anniston. Mullen's first project for the new company was to do contract work for Project Bumblebee, the code name for exploratory research on the ramjet as a means of aircraft propulsion. Frequently, the ramjet was described as a 'flying stovepipe'. What Fenn had not realized when the two talked of the future back in Anniston was that Mullen was easily able to raise the venture capital, almost $\$ 100,000$, to start the company in 1945 [4].

Fenn saw the move to Experiment Incorporated as more interesting and exciting than his job back in Michigan, and in late 1945 joined Mullen and E. Justin Wilson Jr. to form the nucleus of the new company. Interestingly, Fenn's first publication in the scientific literature was at Experiment Incorporated in 1949 [5], almost a decade after taking his doctoral degree from Yale. However, in short order, his research resulted in a steady stream of papers dealing with the field of combustion and flames. During this period, Fenn became a regular figure at meetings on combustion. With a half-dozen publications and an almost equal number of patents (Figure 1) in the field, a new opportunity opened up for him in the mid 1950s.

His old Yale mentor, Professor Akerlof, now at Princeton, dropped Fenn's name in the hat for Director of Project Squid. This project entailed propulsion research for the Office of Naval Research (ONR). ONR funded Princeton and, in turn, they sublet contracts to schools and organizations around the country. Fenn was in essence a contract monitor for Project Squid. The position came with the rank of Professor, albeit without any teaching duties. He was back in academia, a place that he had more or less forsaken after his graduate school experience. However, being heavily involved in the development of a new field of study, he found this academic experience much more exciting.

\section{An Auspicious Turn}

In 1955, Fenn's position led to an opportunity that would start his research in a new direction. He was given the opportunity to spend a year in London as the ONR Laboratory Liaison Officer in Combustion and Propulsion. In this capacity, he traveled to laboratories throughout Europe and interacted with all of the important scientists doing flame and combustion research. In addition, he was not involved in laboratory experiments on a day-to-day basis. In fact, during this period, his publication record is essentially non-existent. He is listed on some patents with Mullen [6, 7], obviously the results of earlier work at Experiment Incorporated, and he gave one paper at an American Rocket Society meeting in 1958 [8]; revealing his penchant for whimsical titles, "Combustion ResearchWhence and Whither," a title that all too accurately reflected Fenn's ambivalence about the field at the time.

Given the opportunity to exchange ideas with colleagues and to sift through the literature, he realized that the complexity of flames mitigated against productive research as he had been approaching it in the past, and concluded that a new attack had to be taken. For several years, Fenn had been interacting with the molecular beam community and he mused over ways in which beam experiments could be applied to the study of flames. Basically, a reactive collision between molecular beams was the route that Fenn saw as productive for further research, but as late as 1955 , no one 
had demonstrated that such an experiment would produce products from the reactants. Upon returning to Princeton in 1956 after his tour of duty abroad, he became aware of the work of Datz and Taylor, producing $\mathrm{KBr}$ from beams of potassium atoms and hydrogen bromide molecules [9]. However, the activation energy of this reaction was way below the 0.5 to $2 \mathrm{eV}$ characteristic of combustion processes. Nevertheless, the success of the $\mathrm{KBr}$ beam experiment kept nagging at Fenn. After additional literature research, he came to realize that heavy molecules, seeded at low levels in a lighter carrier gas such as hydrogen or helium, could be accelerated to suprathermal translational energies in a free-jet expansion. Of course, the expansion would need to be into a vacuum. Vacuum pumps with high pumping speed would be needed to handle the mass flow rate of the carrier gas; very high pumping speed; on the order of tens of thousands liters per second!

The molecular beam apparatus described in the Review of Scientific Instruments in 1963 [10], Fenn's first publication after a 5-year hiatus, had two 32-inch diffusion pumps, one in the nozzle source chamber, and one in the skimmercollimator chamber, to avoid scattering losses.

Even with water cooled baffles between the pumps and the instrument chambers, the pumping speed was between 30,000 and $40,000 \mathrm{~L} / \mathrm{s}$ at pressures on the order of $10^{-9}$ atmospheres! With this equipment in place Fenn's research output took off pretty much like those ramjet powered rockets that he had studied earlier in his career. Before leaving Princeton for Yale in the late 1960s, Fenn and coworkers had published over a dozen papers on various aspects of molecular beams in the journal and government report literature. Fenn had become a leading expert in the field.

\section{A Second Serendipitous Meeting}

Fenn moved his molecular beam apparatus to Yale in the late 1960s and started up his research program again with hardly a hitch in publication output, despite a year delay in moving his equipment. In the next 15 years, Fenn's group produced approximately 45 publications exploring a wide range of topics in molecular beam physics and chemistry. Fenn's reputation for pioneering leadership in the field was recognized in Dudley Herschbach's 1986 Nobel Lecture on "Molecular Dynamics of Elementary Chemical Reactions" [11]. While most of this research had little to do with electrospray ionization, it sharpened his understanding of the various processes in a free jet expansion; knowledge necessary for later application. The next step in his non-linear path to Nobel fame depended on a chance meeting with two other Yale faculty, one in the Medical School and the other in the Engineering Department, facilitated by a third person.

Seymour 'Sandy' Lipsky was a medical doctor who came to Yale as a Research Fellow in 1952, immediately after completing his medical training. By 1966 he had become Professor of Physical Sciences and the Director of the
Section of Physical Sciences at the Medical School [12]. Lipsky had a broad range of interests outside of medicine and was intrigued by instrumental developments in analytical chemistry and how they could be applied to problems in biology and medicine. He became a pioneer in the application of these new and evolving analytical tools to the analysis of biological compounds, publishing extensively on all aspects of chromatography. In 1960, he was credited with the development of the electron capture detector in his collaboration with Lovelock [13]. He also had an interest in mass spectrometry and his 1965 mass spectrometry lab was the forerunner of the Keck Mass Spectrometry Lab in the Yale Medical School formed in 1993. (see http://keck.med. yale.edu/prochem/history.htm ) He was particularly interested in the combination of chromatography with mass spectrometry [14].

Lipsky was instrumental in recruiting Csaba Horvath to the Yale Medical School in 1964. Educated in Europe at the University of Technical Sciences, Budapest Hungary, Horvath received his bachelors degree in chemical engineering in 1952 [15]. He departed Hungary in November of 1956 after the Hungarian revolution and moved to Frankfurt. Completing his doctoral studies at the University of Freiburg in 1963, he immigrated to the United States, taking a Research Fellowship at the Physics Research Laboratory of Massachusetts General Hospital, Harvard University Medical School. A year later, now at Yale, Horvath was to work on the development of HPLC, then known as High Pressure Liquid Chromatography. By 1967, Horvath was appointed as a joint member of the faculty of the Engineering Department. In this latter capacity, Horvath became acquainted with many members of the department. Thus, he was an acquaintance of Fenn, albeit perhaps casually, and a close acquaintance of Lipsky, co-authoring over a dozen papers with him during the late 1970s.

The third person who facilitated bringing together Lipsky, Horvath, and Fenn is Malcolm Dole, a physical chemist who spent the majority of his career at Northwestern University; ironically, the school that had once offered Fenn an opportunity for graduate study. Much of Dole's research centered on the chemistry of polymerization, the effect of radiation on polymers, and the analysis of polymers produced in his studies. In this latter area, Dole published several papers [16-18] in the late 1960s devoted to the development of a new ionization technique for the analysis of synthetic polymers. It involved spraying a dilute solution of a synthetic polymer, originally polystyrene, through a needle at a high voltage, on the order of $10,000 \mathrm{~V}$, under conditions to produce a supersonic jet. The spray entered a chamber with a nozzle-skimmer on the opposite wall with a flow of nitrogen into the chamber to assist in the evaporation of the solvent in the spray droplets. Thus, charged macroions of polystyrene would exit the nozzle-skimmer and proceed toward the Faraday cage detector (Figure 2).

Obviously, no mass spectrometer then had the mass range to separate and detect ions of polystyrene molecules. His 


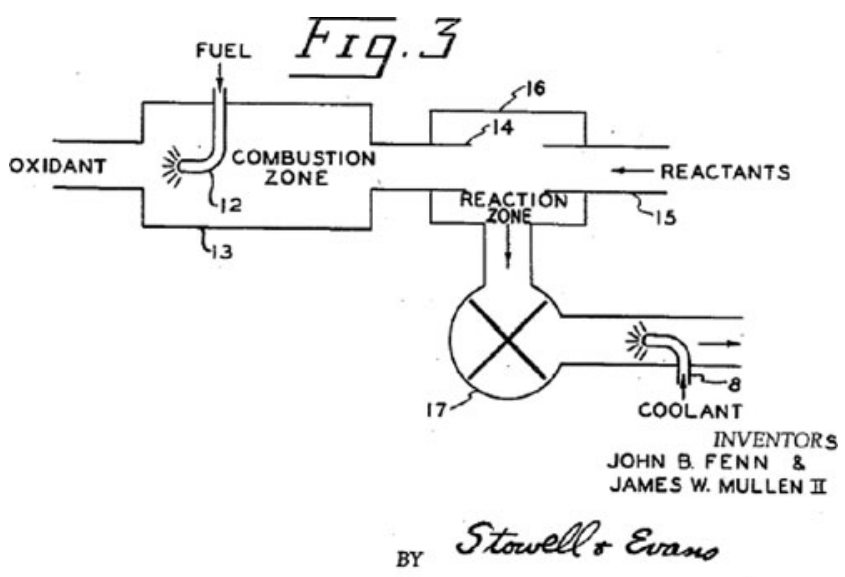

ATTORNEYS

Figure 1. Drawing from early patent on thermal decomposition of hydrocarbons. From Mullen, J. W. II; Fenn, J. B. Acetylene and ethylene by thermal decomposition of hydrocarbons, Patent no. US 2767233 Assigned to Chemical Construction Corporation, 1956, 7 pages

solution was to collect the ions in a Faraday cage behind a repeller grid whose voltage he could vary. Knowing the velocity of the charged polystyrene ions - and assuming their charge state - he could compute the voltage needed to prevent, first the solvent molecules, and then successively heavier styrene $n$-mers from entering the Faraday cage. A typical result from this apparatus showed the current at the Faraday cage decreasing in steps as the increasing retarding potential prevented one more $n$-mer, starting with the lightest to the heaviest, from entering the Faraday cage.

A key element in Dole's 1968 experiment [16] was the assumption that he knew the velocity of the polystyrene $n$ mers exiting the needle; an assumption based on work that Fenn had reported a year earlier [19] and which Dole had referenced. Dole published two additional papers on his research in this area $[17,20]$ while at Northwestern. Several more publications appeared after his move to Baylor University in 1970 [18, 21], but little after 1975.

At some point in the late 1970 s or early 1980 s - the exact point in time is probably lost forever as all of the people

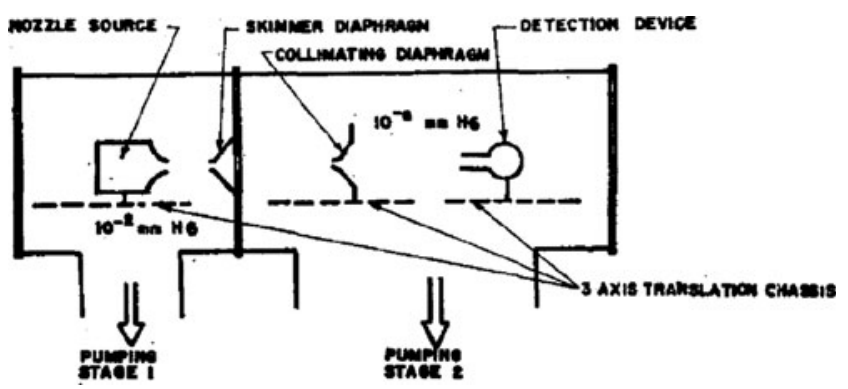

Figure 2. Schematic representation of Fenn's first molecular beam apparatus. Reprinted with permission from Deckers, J.; Fenn, J. B. High-intensity molecular beam apparatus. Rev. Sci. Instrum. 1963, 34, 96-100. Copyright 1963, American Institute of Physics

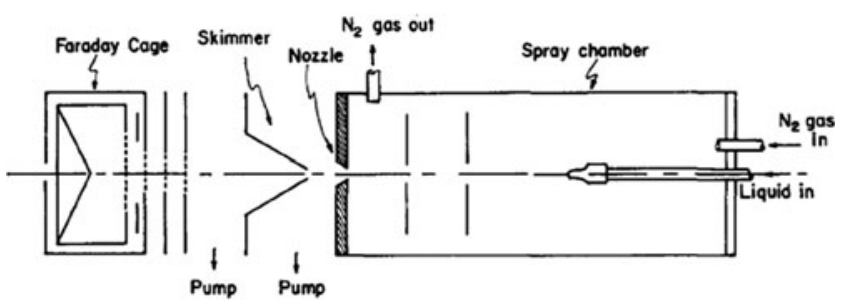

Figure 3. Schematic representation of Dole's electrospray apparatus. Reprinted with permission from Dole, M.; Mack, L. L.; Hines, R. L.; Mobley, R. C.; Ferguson, L. D.; Alice, M. B. Molecular beams of macroions. J. Chem. Phys. 1968, 49, 2240-2249. Copyright 1968, American Institute of Physics

involved have passed on and it doesn't appear that anyone made a note of it - Horvath and Lipsky were reviewing the literature, thinking about alternate ways of ionizing biomolecules. Dole's papers on electrospray were pertinent and in the process of reading through and digging up references, they saw that Fenn had been referred to in two of Dole's publications [16, 17]. Horvath recognized the name and quickly came to the conclusion that the Fenn referenced in Dole's papers was one and the same as the Fenn in the Yale Engineering Department. In short order, Fenn was drawn into the discussion of Dole's electrospray research and encouraged to build on Dole's work to see what might come of it. Fenn had a much more sophisticated grasp of the physics occurring in a free jet expansion, so he should be able to rapidly further research in the area. In addition, perhaps electrospray ionization opened up new possibilities for the combination of the liquid chromatograph with the mass spectrometer?

It is an interesting commentary on Fenn's intellectual curiosity and energetic character that he accepted the challenge to begin research on the problem of adapting his molecular beam apparatus to combining the two analytical tools, even as he was approaching 65 , typical retirement age. In 1983, the Department of Chemical Engineering organized and hosted a conference, "Nozzle Molecular Beams-A Fennfest." The Journal of Physical Chemistry published 23 of those papers in a 1984 issue dedicated to Fenn [3]. He easily could have retired from a successful and rewarding career, much more intellectually exciting and challenging than he ever could have guessed when he left Yale with his newly minted Ph.D. in 1940. Instead, he turned his complete attention to the problem that Lipsky and Horvath had presented. By 1987, he even had to fight with Yale for lab space as well as funding agencies for resources [2] to carry the work forward. Only four of his 40 or so publications after 1983 dealt with his previous research on molecular beams. Among his earliest publications in this new area were patents filed in 1983 in the United States on various aspects of the electrospray ion source [22, 23] that were granted in 1985.

At this point, many would argue that 'the rest is history', well-known to all of us. But the reality was a bit more complicated. Acceptance of electrospray ionization as a 
means of coupling the liquid chromatograph and mass spectrometer came slowly at first. Fenn was entering an area of research already crowded with teams of researchers working on the problem, and was considered by many as an interloper. He remarks on this himself in comments to the Young Mass Spectrometrists Workshop at the American Society for Mass Spectrometry Conference in 1994 [24]. One of the recommendations he made to the young Turks was in reference to the difficulty he had had in gaining traction in this new area of research: "Join a clubxenophobia still lives (cited his difficult entry into the mass spectrometry community)."

All the other researchers for combining the two analytical techniques had credibility in the mass spectrometry community and many had some very promising approaches. By 1983, the basic research for atmospheric pressure chemical ionization (APCI) was being done in Canada $[25,26]$, and thermospray ionization (TSI) had arrived on the scene [27, $28]$ as viable candidates for the LC-MS interface problem. That didn't count the numerous other interfaces reviewed in Arpino and Guiochon's 1979 article in Analytical Chemistry [29]. It didn't help Fenn and coworkers either to gain credibility when they published their earliest results in the Journal of Physical Chemistry [30, 31] — a logical choice for molecular beam work - and the Japanese journal Iyo Masu Kenkyukai Koenshu [32] in deference to Fenn's talented postdoctoral group member, Masamichi Yamashita.

Finally, in 1985, Fenn's group published a paper in Analytical Chemistry [33], perhaps at the insistence of Lipsky, who despite his M.D. degree published no less than 12 articles in Analytical Chemistry in as many years. In addition, Fenn or a member of his group began to appear regularly at the ASMS Conference on Mass Spectrometry and Allied Topics in 1983 and to present papers on the development of electrospray in 1984. Slowly, his ideas about ionization were getting more attention in the mass spectrometry community, and by the late 1980s, numerous references to his work began to appear in papers presented at the Annual Conference. Fenn himself marks the 1988 Conference as the moment of acceptance [2] by the mass spectrometry community:

"These findings . . . were first presented at the annual meeting of the American Society for Mass Spectrometry in San Francisco in 1988. Only 15 or 20 people were in the room but after that presentation, what has been called the Electrospray Revolution spread rapidly."

In retrospect, one wonders why Malcolm Dole did not succeed at electrospray ionization and John Fenn did. Their basic instrumental approaches were very much the same. His group certainly had a better fundamental understanding of the free jet expansion and that helped significantly in their development of the electrospray ion source. Fenn maintains that an important difference between the two approaches to electrospray was the introduction of the drying gas against the incoming spray. (Compare the entry point of nitrogen in Figures 3 and 4) Fenn's molecular beam apparatus was better as well. Dole's detection technique did not provide enough information about the ions that made it into the Faraday cage. They were charged and they could be separated into groups with different charge-to-mass ratios. Here, Fenn saw the need to work with simpler, smaller starting compounds in the proof-of-principle stage. Thus, he used compounds whose mass was within the limited mass range of his quadrupole mass filter.

But Fenn admits that he too couldn't see a solution to the problem of detection of high mass ions [2]. It was well accepted that large ions from biomolecules needed to be accelerated to much higher energies than were present or practical in the equipment they had if they were to be detected with electron multipliers. This problem disappeared when it was realized that the multiply-charged ions in the mass spectrum of electrosprayed proteins could be deconvoluted to provide the parent ion mass of the protein [34]. What had seemed a hindrance to most in the mass spectrometry community, the confusing, multi-peak spectrum of a pure biomolecule, was in fact a boon to the ionization technique. The mass range and detectors of existing mass spectrometric instrumentation were sufficient to analyze high molecular weight biomolecules when equipped with an electrospray ion source. Furthermore, the ion source was compatible with the liquid chromatograph as a sample inlet. The obvious merits of this approach were apparent to those in the biological community who wanted to use mass spectrometry in their research, and it was adopted rapidly in the early 1990s.

Fenn has always been very generous with crediting his colleagues in his research. From the earliest papers he published on electrospray ionization, he referenced Dole's seminal work. He even had the pleasure of meeting Dole at

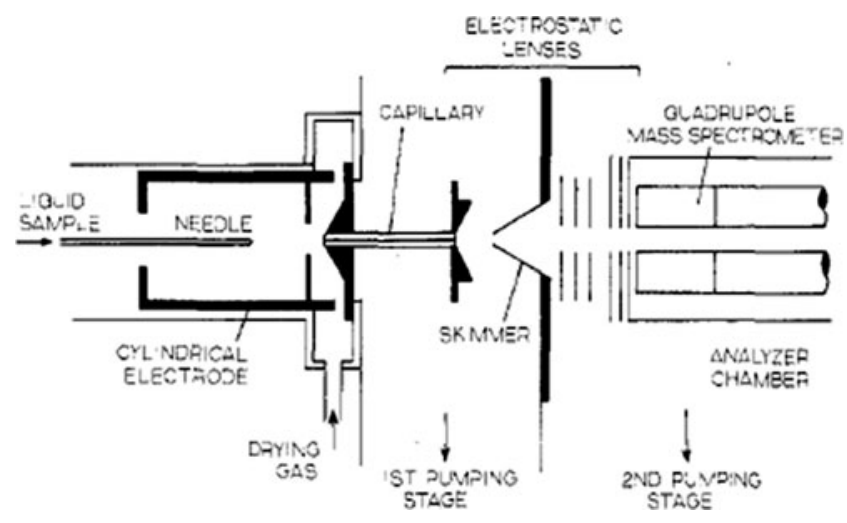

Figure 4. Schematic representation of Fenn's electrospray apparatus. Reprinted with permission from Whitehouse, C. M.; Dreyer, R. N.; Yamashita, M.; Fenn, J. B. Electrospray interface for liquid chromatographs and mass spectrometers. Anal. Chem. 1985, 57, 675-679. Copyright 1985 American Chemical Society 


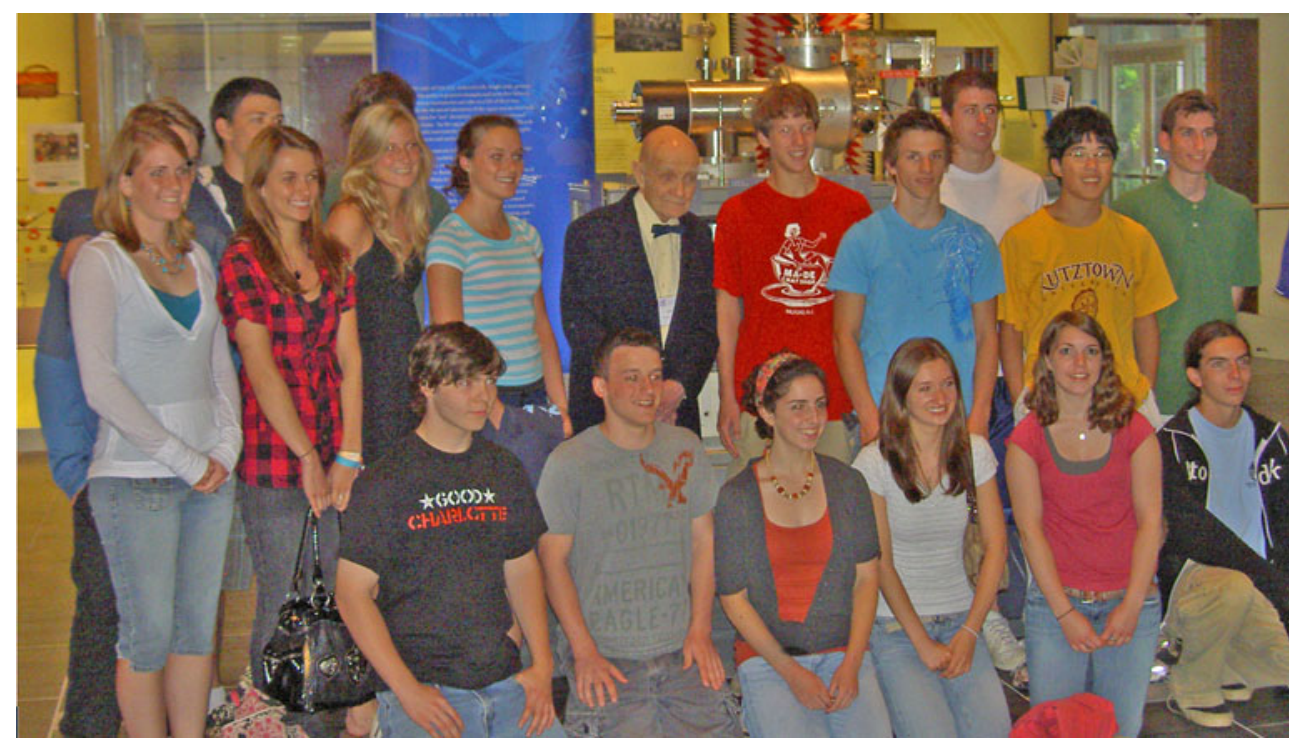

Figure 5. Fenn poses for an impromptu photograph with students touring the 'Making Modernity' exhibit at the Chemical Heritage Foundation in 2009. Photo by author

the 1985 ASMS Conference [35] and exchanging ideas on the electrospray process. During the development of the electrospray ion source and using it in the combination of the liquid chromatograph and mass spectrometer, Fenn repeatedly mentions the valuable contributions of members of his group. In particular, Mike Labowsky, Masamichi Yamashita, Craig Whitehouse, Shek Fu Wong, Chin Kai Meng, and Matthias Mann. In his retrospectives [1, 2], he mentions the important role that his Yale colleagues Sandy Lipsky and Csaba Horvath played in pointing him to an area of research that ultimately gained him the most coveted award in the world of science.

\section{Nobel 2002}

The Nobel Committee always provides a very short, clear, and concise summary of why a recipient is being honored. In the Committee's assessment, Fenn shared the prize with Koichi Tanaka "for their development of soft desorption ionization methods for mass spectrometric analyses of biological macromolecules." What is not said, but implied, is that the development is significant, and that the honorees are the first to publish the research. Clearly, the development of electrospray ionization is significant. Today, typically 100 papers a year are published on the specific topic of "electrospray ionization in the analysis of biomolecules," a rather restrictive search, but one in consonance with the Nobel Committee's reason for the Award. A more general search on "electrospray ionization and 2010" brings up between 1900 and 4200 citations depending upon the search engine! Even more research is performed using this ionization technique that isn't published. While some would argue that Dole should get more credit, the fact is that Fenn created a practical electrospray ion source and doggedly pursued solutions to problems that were critical to the success of the ionization technique and its use in the combination of the liquid chromatograph with the mass spectrometer.

Perhaps there are those very ambitious scientists who start out their careers with the ultimate goal of securing a Nobel Prize in mind. If such individuals exist, they should most definitely read Robert Friedman's book, The Politics of Excellence: Behind the Nobel Prize in Science [36]. Clearly, John Fenn did not have such a goal at the beginning of his career. He simply took advantage of each opportunity that came his way and made the best of it. The path that he took had twists and turns that few would have plotted if the Prize was their goal. Perhaps the most striking thing about Fenn's Nobel Prize is the fact that it was awarded for work that he performed essentially after he was forced to retire while holding an emeritus position at Yale! Of the chemistry laureates, Fenn was the oldest when he received the prize at the age of 85 and a half years, for work he had done less than two decades earlier. (see http://en.wikipedia.org/wiki/ List_of_Nobel_laureates_in_Chemistry_by_age). Unfortunately, we don't have statistics on the age of laureates when they did their prize winning research, but I suspect that Fenn is oldest in that category as well.

\section{Epilogue}

As the finishing touches were put on this publication, news of John Fenn's death on the December 10, 2010 reached me. I had the pleasure and honor of conducting an oral history interview of John Fenn in 2008 and recall fondly the experience of our meeting.

Recognition by the Nobel Committee changes a scientist's life immediately (Figure 5). The Nobel Prize is perhaps the most successful and prestigious 'brand' in the world. The caller from Stockholm in 2002 at 5:00 in the morning warned Fenn that his phone would start ringing as soon as he hung up. It did, 
and the first call was from a reporter covering the news desk in Brazil! Just about everyone worldwide understands the significance of the award, and the recipient is viewed in awe as a giant in his field by both fellow scientists and the man on the street.

Thus, it was with some trepidation that I met John for the oral history interview. He came to pick me up at my lodging rather than have me try and find my way to his home. A young Virginia Commonwealth student provided chauffeur service. As soon as the vehicle pulled up, John literally hopped out of the passenger's seat of the van and ran over to greet me with a hearty hand shake. He then led me around to the seat that he had just vacated and insisted that I sit in the front passenger seat while he sat in the back. He subsequently had the driver take a mini-tour of Richmond to point out for me historic points of interest and architecturally important buildings. John Fenn had received the most prestigious honor in all of science, but he was still that Southern Gentleman from Berea College.

\section{References}

1. Fenn, J.B.: Electrospray wings for molecular elephants (Nobel lecture). Angew. Chem. Int. Ed. 42, 3871-3894 (2003)

2. Fenn, J.B.: Research in retrospect: Some Biograffiti of a Journeyman Chemist. Annu. Rev. Phys. Chem. 47, 1-41 (1996)

3. Kolb, C.E., Herschbach, D.R.: John Bennett Fenn. J. Phys. Chem. 88, 4447-4448 (1984)

4. Chemical \& Engineering News 1948; Vol. 26, p. 2554-2555.

5. Mullen, J. W. II; Fenn, J. B.; Irby, M. R. In Third Symposium on Combustion, Flame, and Explosion Phenomena; Williams \& Wilkins Co.: 1949; Vol. 204-9, p. 317-329.

6. Mullen, J. W. II; Fenn, J. B., Acetylene and ethylene by thermal decomposition of hydrocarbons, Patent no. US 2767233 Assigned to Chemical Construction Corp. 1956, no. pages 7.

7. Mullen, J. W. II; Fenn, J. B. Partial oxidation of hydrocarbons, Patent no. US 2722553 Assigned to Chemical Construction Corp. 1955, no. pages 7.

8. Fenn, J. B. In American Rocket Society 1958; Vol. 686, p. 11.

9. Datz, S., Taylor, E.H.: Ionization on platinum and tungsten surfaces. II. The potassium halides. J. Chem. Phys. 25, 395-397 (1956)

10. Deckers, J., Fenn, J.B.: High-intensity molecular beam apparatus. Rev. Sci. Instrum. 34, 96-100 (1963)

11. Nobel Lectures, Chemistry 1981-1990, Editor-in-Charge Tore Frängsmyr, Editor Bo G. Malmström, World Scientific Publishing Co., Singapore, 1992.

12. Horvath, C.: Complimenting Sandy Lipsky on His Sixtieth Birthday. Chromatographia 18, 351-352 (1984)

13. Lovelock, J.E., Lipsky, S.R.: Electron affinity spectroscopy-a new method for the identification of functional groups in chemical compounds separated by gas chromatography. J. Am. Chem. Soc. 82, 431-433 (1960)

14. Lipsky, S.R., Horvath, C.G., McMurray, W.J.: Utilization of System Employing the Selective Permeation of Helium through a Unique
Membrane of Teflon as an Interface for a Gas Chromatograph and Mass Spectrometer. Anal. Chem. 38, 1585-1587 (1966)

15. Ettre, L.S.: In Memoriam: Csaba Horvath (1930-2004). J. Capillary Electrophor. Microchip Technol 9, 2A-3A (2004)

16. Dole, M., Mack, L.L., Hines, R.L., Mobley, R.C., Ferguson, L.D., Alice, M.B.: Molecular beams of macroions. J. Chem. Phys. 49, 22402249 (1968)

17. Mack, L.L., Kralik, P., Rheude, A., Dole, M.: Molecular beams of macroions. II. J. Chem. Phys. 52, $4977-4986$ (1970)

18. Dole, M., Cox Jr., H.L., Gieniec, J.: Electrospray mass spectroscopy. In: Ezrin, M. (ed.) Advances in Chemistry Series, Vol. No. 125, pp. 73-84. American Chemical Society, Washington DC (1973)

19. Abuaf, N., Anderson, J.B., Andres, R.P., Fenn, J.B., Marsden, D.G.H.: Molecular beams with energies above one electron volt. Science (Washington, DC) 155, 997-999 (1967)

20. Dole, M., Hines, R.L., Mack, L.L., Mobley, R.C., Ferguson, L.D., Alice, M.B.: Gas phase macroions. Macromolecules 1, 96-97 (1968)

21. Clegg, G.A., Dole, M.: Molecular beams of macroions. III. Zein and poly(vinylpyrrolidone). Biopolymers 10, 821-826 (1971)

22. Labowsky, M. J.; Fenn, J. B.; Yamashita, M. Method and Apparatus for the Mass Spectrometric Analysis of Solutions, Patent no. US 4531056 Assigned to Yale University. 1985, no. pages 19.

23. Fenn, J. B.; Yamashita, M.; Whitehouse, C., Process and Apparatus for Changing the Energy of Charged Particles Contained in a Gaseous Medium, Patent no. US 4542293 Assigned to Yale University. 1985, no. pages 12

24. Amster, J. Proceedings of the 42nd ASMS Conference on Mass Spectrometry and Allied Topics Chicago, IL, 1994.

25. Thomson, B.A., Iribarne, J.V.: Field-induced ion evaporation from liquid surfaces at atmospheric pressure. J. Chem. Phys. 71, 4451-4463 (1979)

26. Thomson, B.A., Iribarne, J.V., Dziedzic, P.J.: Liquid ion evaporation/ mass spectrometry/mass spectrometry for the detection of polar and labile molecules. Anal. Chem. 54, 2219-2224 (1982)

27. Liberato, D.J., Fenselau, C.C., Vestal, M.L., Yergey, A.L.: Characterization of glucuronides with a thermospray liquid chromatography/mass spectrometry interface. Anal. Chem. 55, 17411744 (1983)

28. Blakley, C.R., Vestal, M.L.: Thermospray interface for liquid chromatography/mass spectrometry. Anal. Chem. 55, 750-754 (1983)

29. Arpino, P. J.; Guiochon, G. LC/MS coupling. Anal. Chem. 51, 682A684A, 688A, 690A, 692A, 697A--698A, 700A-701A (1979)

30. Yamashita, M., Fenn, J.B.: Electrospray ion source. Another variation on the free-jet theme. J. Phys. Chem. 88, 4451-4459 (1984)

31. Yamashita, M., Fenn, J.B.: Negative ion production with the electrospray ion source. J. Phys. Chem. 88, 4671-4675 (1984)

32. Yamashita, M., Fenn, J.B.: Application of electrospray mass spectrometry in medicine and biochemistry. Iyo Masu Kenkyukai Koenshu 9, 203-206 (1984)

33. Whitehouse, C.M., Dreyer, R.N., Yamashita, M., Fenn, J.B.: Electrospray interface for liquid chromatographs and mass spectrometers. Anal. Chem. 57, 675-679 (1985)

34. Fenn, J.B., Mann, M., Meng, C.K., Wong, S.F., Whitehouse, C.M.: Electrospray ionization for mass spectrometry of large biomolecules. Science (Washington, DC) 246, 64-71 (1989)

35. Dole, M. Proceedings of the 33rd ASMS Conference on Mass Spectrometry and Allied Topics; San Diego, CA, 1985.

36. Friedman, R.M.: The Politics of Excellence: Behind the Nobel Prize in Science, 1st edn. Henry Holt and Company, New York (2001) 